\title{
EVALUATION OF NEONATAL READMISSIONS IN THE NOTTINGHAM AREA
}

\author{
S. McAllister ${ }^{1}, \mathrm{H}$. Budge ${ }^{2}$, D. Jayasinghe ${ }^{1}$ \\ ${ }^{I}$ Neonatal Unit, ${ }^{2}$ Academic Child Health, Nottingham University Hospital, Nottingham, UK
}

Background: Neonatal readmissions are an important group of hospital attendances. They have been used as a proxy measure for neonatal health and wellbeing and are associated with significant healthcare costs[1] as well as costs to the family. We evaluated neonatal readmissions in Nottingham, in which around 10000 babies are born p.a. We hypothesised that there is an emerging pattern of diagnoses requiring readmission.

Methods: We analysed birth and admission data for all babies born between $1^{\text {st }}$ December 2009 and $31^{\text {st }}$ March 2010 who were subsequently readmitted to local hospitals within the first 28 days of life. Cases were attained by reviewing contemporaneous admission logs and birth records with subsequent case note review..

Results: Of the 3286 babies born during this time, there were 168 admissions within the neonatal period of which 71 were excluded as interdepartmental transfers, repeated or planned admissions. In $25 \%$ of cases, infants were admitted following difficulty in establishing breastfeeding, of whom ten had hypernatraemic dehydration. Other common diagnoses were: jaundice, infections and bronchiolitis. Twenty infants were admitted with hypothermia associated with sepsis, failure to establish feeding or without clear cause.

Conclusions: This study illustrates an emerging new distribution of diagnoses within those babies readmitted in the neonatal period with a significant number of infants readmitted with feeding difficulties, significant weight loss and dehydration. This work illustrates the need for future work on prevention of this now common issue.

[1] Radmacher P, Massey C, Adamkin D. Hidden morbidity with "successful" early discharge. J Perinatol. 2002 Jan;22(1):15-20 